Review

\title{
Current status and future directions of cancer immunotherapy
}

\author{
Hongming Zhang, Jibei Chen ${ }^{\bowtie}$ \\ Department of Respiratory Medicine, Yancheng Third People's Hospital, the Affiliated Yancheng Hospital of Southeast University Medical College, Yancheng, \\ Jiangsu, China. \\ $\triangle$ Corresponding author: Jibei Chen, MD., Chair, Director of Department of Respiratory Medicine, Yancheng Third People's Hospital, Jiangsu Province, P.R. \\ China. E-mail: hmzhang149252@163.com \\ (C) Ivyspring International Publisher. This is an open access article distributed under the terms of the Creative Commons Attribution (CC BY-NC) license \\ (https://creativecommons.org/licenses/by-nc/4.0/). See http://ivyspring.com/terms for full terms and conditions.
}

Received: 2017.12.26; Accepted: 2018.02.05; Published: 2018.04.19

\begin{abstract}
In the past decades, our knowledge about the relationship between cancer and the immune system has increased considerably. Recent years' success of cancer immunotherapy including monoclonal antibodies (mAbs), cancer vaccines, adoptive cancer therapy and the immune checkpoint therapy has revolutionized traditional cancer treatment. However, challenges still exist in this field. Personalized combination therapies via new techniques will be the next promising strategies for the future cancer treatment direction.
\end{abstract}

Key words: cancer, immune system, cancer immunotherapy, challenges, future directions

\section{Background}

For decades, the conventional anticancer treatment strategies have been surgery, chemotherapy, and radiotherapy [1,2]. While many of these therapies have offered substantial benefit for eradication of primary tumors, the incidence of disease relapse is still a commonly encountered problem that results from residual malignant cells and/or tumor metastases [3, 4]. Therefore, alternative treatment approaches to eliminate the resistant tumor cells are warranted [5].

Cancer immunotherapy is becoming an appealing and attractive strategy among different therapeutic options over the past years and has showed its power against malignancies (Figure 1) [3, 6-9]. It utilizes the body's immune system to induce anti-tumor response and thus cancer can be defeated $[3,6-9]$. Most recently, cancer immunotherapy field is growing tremendously, such as utilization of cancer vaccinations, chimeric antigen receptor (CAR) T-cell therapy and immune checkpoint blockade therapy $[10,11]$. Several clinical trials have investigated their potentials in cancer patients lifesavings [12-16], and after witnessing the amazing effect of cancer immunotherapy it was selected as "2013's
Breakthrough of the Year" by Science magazine [17].

Our goal in this article is to concisely summarize the molecular bases of immune system and its relationship with cancer as well as recent developments in cancer immunology. Cancer immunotherapeutic drugs and their clinical applications will also be discussed in details. Finally, challenges and future directions of cancer immunotherapy will be provided based on the previous clinical studies. We hope that this review will be of interests to both basic cancer immunologists and also clinical oncologists.

\section{Cancer and the immune system}

The relationship between immune system and cancer has been extensively investigated in numerous preclinical and clinical studies [18-22]. The basic role of our immune system is to protect human beings against foreign pathogens and also infections. The immune responses consist of two types: humoral immunity and cellular immunity, which are mediated by $\mathrm{B}$ and $\mathrm{T}$ lymphocytes as well as their products [23]. Humoral immunity can neutralize and eradicate outside microbes and toxins via antibodies produced 


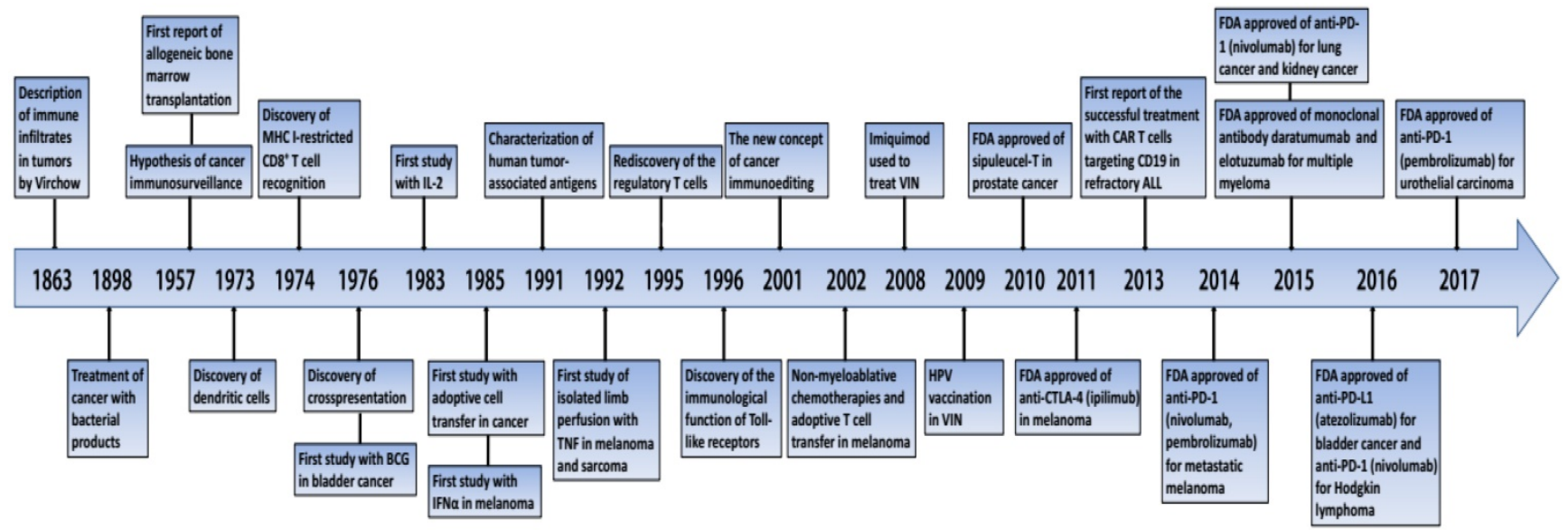

Figure 1. Important events in the history of cancer immunotherapy. BCG, bacilli Calmette-Guérin; CTLA-4, cytotoxic T lymphocyte-associated antigen-4; FDA, Food and Drug Administration; IFNa, interferon-a; IL-2, interleukin-2; MHC, major histocompatibilty complex; PD-1, programmed death 1; TNF, tumor necrosis factor; VIN, vulvar intraepithelial neoplasia

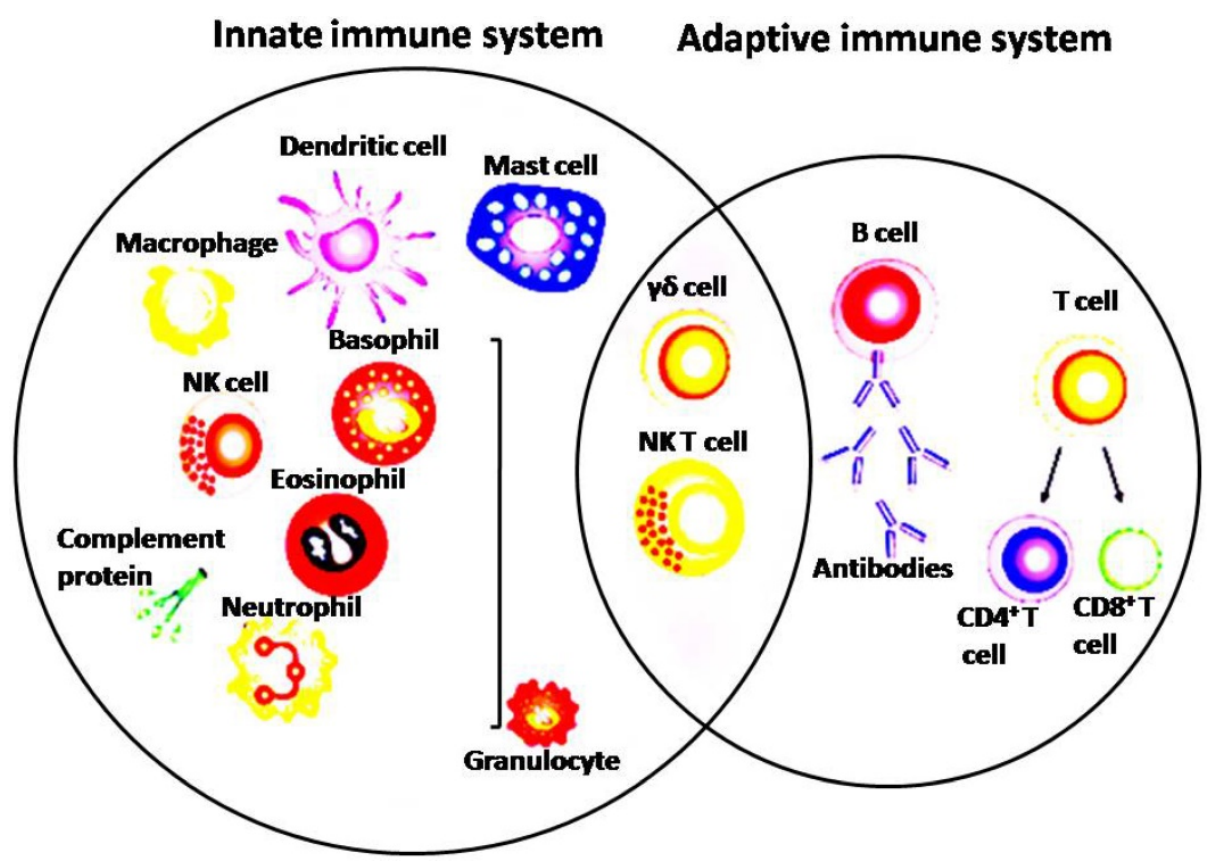

Figure 2. Depicture of cells in the innate and adaptive immune system

by $B$ cells [24-26], whereas cellular immunity responds more quickly to eradicate intracellular microbes through recognition of antigens, activation of antigen presenting cells (APCs), activation and proliferation of T cells. [23, 27, 28].

Both innate and adaptive immune systems play important roles in anticancer immune response (Figure 2) [29, 30]. The innate immune cells can release signals which are essential to stimulate responses from both $\mathrm{T}$ cells and $\mathrm{B}$ cells [31]. Adaptive immune system is mainly consists of $\mathrm{B}$ cells, $\mathrm{CD} 8^{+}$ cytotoxic T cells as well as $\mathrm{CD}^{+}{ }^{+}$helper $\mathrm{T}$ cells [32]. APCs is performing as a bridge between the innate and the adaptive immune system by recognizing foreign antigens and presenting to the naive $T$ cells [33]. In addition, after activation of toll-like receptors on dendritic cells (DCs), factors on the DC surface that is essential to antigen presentation could be increased and cytokines that facilitate the adaptive immune response would be promoted [33]. It has now been widely accepted that by the cooperativity of innate and adaptive immune system can lead to complete success of conquering cancer [34]. $\mathrm{CD}^{+}$cytotoxic $\mathrm{T}$ lymphocytes (CTLs) are considered as the corner stone of immune response fighting cancer [7]. Tumor-infiltrating lymphocytes (TILs) contain an abundant level of CTLs capable of invading malignant cells [35]. Tumor antigen recognition is a necessary prerequisite for the effective antitumor immune response [3]. Tumor antigen presentation is mediated by direct presentation which cancer cells drain in the lymph node or via cross-presentation by 
pAPC [36]. Cross priming of naïve $\mathrm{CD}^{+} \mathrm{T}$ cells by pAPC invokes a program leading to tumor specific CTLs proliferating and trafficking to the tumor sites where they will finally attack cancer cells [37]. CTLs can attack tumor cells via perforin, granzymes and also ligands of the tumor necrosis factor (TNF) superfamily [38]. The anti-tumor effect can also be achieved by secreting Interferon gamma (IFN- $\gamma$ ) and TNF- $\alpha$ from activated $\mathrm{CD}^{+} \mathrm{T}$ cells [39]. Naive $\mathrm{CD} 4^{+} \mathrm{T}$ cells could be activated and differentiated into distinct T cell subsets such as Th1, Th2, Tregs, Th9, Th17, Th22 and also follicular helper $T$ cells once they encounter antigens and also adequate co-stimulation signals [40]. Th1 subset of $\mathrm{CD}^{+} \mathrm{T}$ cells play crucial antitumor roles by coordinating cell mediated immunity against cancer. Th1 cells can produce IFN- $\gamma$ and chemokines and thus enhancing $\mathrm{CD} 8^{+} \mathrm{T}$ cells expansion, priming and infiltration into the tumor site by [41]. Th1 cells can also activate inflammatory cells, such as macrophages, NK cells, granulocytes and eosinophils in around the tumor [41]. Th1 cells can kill MHC-II ${ }^{+}$ tumor cells by releasing perforin and granzyme, and also by TNF-related apoptosis inducing ligand (TRAIL) receptor and Fas/Fas ligand pathways [41]. NK cells can destroy cancer cells directly via mechanisms as follows: secretion of TNF- $\alpha$, perforin, cytoplasmic granules and granzymes, expression of death receptor-mediated apoptosis, and expression of CD16 which leads to antibody dependent cellular cytotoxicity (ADCC) [42]. NK cells have been able to have antitumor activity as well indirectly by chemokines, cytokines and growth factors production. The role of macrophages in eliminating apoptotic tumor cells also can't be ignored [42, 43]. Macrophages are an essential component of tumor stroma and tumor-associated immune dysfunction, which can be characterized as pro-inflammatory M1 or anti-inflammatory M2 macrophages [44-46]. M1 macrophages secrete pro-inflammatory cytokines boost antitumor immunity, whereas M2 macrophages produce anti-inflammatory cytokines which would promote tumorigenesis [45]. Myeloid-derived suppressor cells (MDSCs) are both immature and immunosuppressive cells increasing in inflammatory diseases, particularly tumors. They can produce inhibitory factors such as IL-10 and arginase to inhibit $\mathrm{T}$ cells and promote Tregs and detrimental M2 macrophages, and thus suppressing anti-tumor immunity $[47,48]$.

According to the concept of cancer immunosurveillance proposed by Burnet, Thomas and Medawar[49-57], it is now well established that the immune system's capability for spontaneously recognizing cancer cells that had undergone genetic aberrations and mounting a cytotoxic response through the generation of specific $\mathrm{CD}^{+} \mathrm{T}$ lymphocytes. However, this specific $\mathrm{CD} 8^{+} \mathrm{T}$ lymphocytes response ultimately fails due to cancer invasion [58-60]. Cancer immunoediting has been considered for relying on three phases: an early elimination phase with the activation of an innate and adoptive immune response, an equilibrium phase where the sporadic tumor cells may survive immune attacks, and an immune escape phase that the cancer cell variants survive in the immunosuppressive microenvironment by altering geno- or antigenic phenotype or under the control of immunoregulatory phenomena [61]. In this process, the immune system plays contradicting roles for both protecting body from tumor development however also promoting tumor progression [61].

\section{Current cancer immunotherapy strategies}

At present, new strategies aiming at blocking of immune checkpoint regulators, overcoming immune tolerance such as engineered $\mathrm{T}$ cell therapy, or the identification of novel tumor antigens through next-generation sequencing opened a new era of cancer immunotherapy [62-64]. Cancer immunotherapy includes passive or active immunotherapy (Table 1) $[65,66]$. Passive immunotherapy is administration of agents such as mAbs, lymphocytes or cytokines that enhance existing anti-tumor response [34]; active immunotherapy attempts to stimulate self-immune system to attack tumor cells via vaccination, non-specific immunomodulation, or targeting specific antigen receptors [34]. Promising methods were discussed below.

Table 1. Classification of cancer immunotherapy

\begin{tabular}{llll}
\hline Passive immunotherapy & \multicolumn{2}{l}{ Active immunotherapy } \\
\hline $\begin{array}{l}\text { Immunomodulating } \\
\text { antibodies }\end{array}$ & Adoptive immunotherapy & Specific & Non-specific \\
- Immune checkpoints & - Tumor-infiltrating & - Vaccines & - Immune \\
$\begin{array}{l}\text { inhibitors } \\
\text { - Immune }\end{array}$ & lymphocytes & & adjuvants \\
co-stimulatory & - TCR gene-modified & & - Cytokines \\
antibodies & lymphocytes & & \\
& - Chimeric antigen & & \\
& receptors (CARs) & & \\
\hline
\end{tabular}

\section{Monoclonal antibodies}

Antibodies are modified proteins aimed at to target a specific part of deregulated signals transduction pathways in cancer or interfere with immunological processes [57, 67]. FDA has already approved more than a dozen mAbs for the treatment of both solid and hematological malignancies, and also more new mAbs clinical trials are now being investigated [67, 68]. Monoclonal antibody and gene transfer technologies have promoted further exploitation of our fundamental knowledge on 
antigen recognition, $\mathrm{T}$ cell activation as well as $\mathrm{T}$ cell co-stimulation, thus leading to the invention and also the success of checkpoint blockade and CAR $\mathrm{T}$ cell therapy [69]. Several types of mAbs are being used in cancer treatment now, including naked, conjugated and bipecific $\mathrm{mAbs}[70,71]$. Naked $\mathrm{mAbs}$ are the most common type of mAbs for treating cancer, and it can work via boosting the immune response against cancer cells and acting as a marker for the immune system's destroying them. Alemtuzumab is an example of naked $\mathrm{mAb}$ which can bind to the CD52 antigen on lymphocytes attacking them which is used to treat chronic lymphocytic leukemia (CLL) [72, 73]. Other naked mAbs work mainly by attaching to and blocking antigens on tumor cells helping cancer cells grow and spread, like trastuzumab, an antibody against the HER2 on breast and stomach cancer cells [74]. Conjugated mAbs are those mAbs joining to a chemotherapy agent or a radioactive particle taking one of these substances directly to the cancer cells [75]. Chemolabled antibodies are those antibodies with powerful chemotherapy attached to them, such as brentuximab vedotin an antibody that targets CD30 antigen found on lymphocytes, attaching to a chemotherapy drug and thus treating Hodgkin lymphoma and anaplastic large cell lymphoma [76-78]. Radiolabeled antibodies have radioactive particles attached to them [79]. Bispecific mAbs are made up of parts of 2 different mAbs, like blinatumomab binding to both CD3 and CD19 used to treat acute lymphocytic leukemia (ALL) [80, 81]. Possible side effects of mAbs may include fever, chills, headache, weakness, nausea, diarrhea, rashes and hypotension [82].

\section{Cancer vaccines}

Cancer vaccines are the response modifiers working by stimulating or restoring the ability of immune system to fight cancer [83]. It consists of preventive vaccines and therapeutic vaccines [84]. The goal of preventive vaccine is preventing cancer from developing. They are based on antigens carried by infectious agents and easy for the immune system to recognize as foreign invaders [85]. FDA has approved hepatitis B virus (HBV) vaccines and human papilloma virus (HPV) vaccines [84, 86, 87]. It stimulates the immune system with tumor antigens, peptides, or whole cancer cells [88]. The mechanism involves activating the immune system with targeted $\mathrm{T}$ cells to destroy target cancer cells. Therapeutic vaccines first directly target the immune system and expand the immune system's attack on cancer cells. A broadening of the immune response may also be observed as it might attack additional tumor-specific antigens (antigen spread) [57, 89]. In this therapy, peripheral blood mononuclear cells are isolated from the patient and ex vivo activated with a recombinant fusion protein consisting of a prostate antigen prostatic acid phosphatase (PAP) conjugated with granulocyte-macrophage colony-stimulating factor (GM-CSF), and the cells are then re-infused into the patient to activate PAP-specific T cells [90]. T-VEC can trigger an antitumor immune response in non-injected lesions. The side effects of cancer vaccines vary from different vaccine formation and person, and the most commonly reported side effect of cancer vaccines is inflammation at the site of injection [91].

\section{Adoptive $\mathbf{T}$ cell therapies and $\mathbf{T}$ cell engineering}

Adoptive cell transfer (ACT) of tumor-associated antigen-specific $\mathrm{T}$ cells is a very attractive form of immunotherapy for hematologic malignancies as well as solid cancers [92]. Initial studies of ACT utilizing tumor-infiltrating lymphocytes (TILs) have promising clinical results in metastatic melanoma patients to some degree [17, 93]. But later on this approach had been limited by the difficulty in expanding viable TILs and only showing specific effector functions [94]. In order to overcome this problem, strategy of CAR- and $\mathrm{T}$-cell receptor (TCR)-engineered $\mathrm{T}$ cells have been developed based on various approaches by genetic modifications, and inspiring efficacy in various clinical trials for particular cancers have been observed $[95,96]$.

Traditionally, two major sources of $\mathrm{T}$ cells for $\mathrm{ACT}$ are the tumor itself and the peripheral blood of the cancer patient [92]. Transferring of antigen-specific TCR genes into lymphocytes isolated from the patient's peripheral blood becomes an alternative approach [95, 97]. It is via $\mathrm{T}$ cell transductions with retroviruses or lentiviruses, thus they can express TCRs targeting specific cancer antigens and eradicate those cancer cells [97]. Although promising results have been achieved in metastatic melanoma patients, TCR technology seems less attractive because it is MHC-restricted which limited its further development [98]. CAR modified T cells are a second class of engineered T cells [99]. Compared to TCRs, CARs have antibody-like specificities which can recognize major histocompatibility complex (MHC)-non-restricted structures on the surfaces of target cells, thereby allowing for cancer cell recognition in the MHC-unrestricted manner [100]. CAR is composed of an antigen-binding single-chain variable fragment $(\mathrm{scFv})$ domain, a transmembrane domain (TMD) and a signal transduction domain (STD) [101]. ScFv is designed to target a specific surface molecule on $\mathrm{B}$ cells [101]. By altering the changeable components of a 
CAR like the epitope-recognition part, cell function could be improved [100]. CAR constructs also differ in flexibility and length of the hinge region conjoining the $\mathrm{scFv}$ to the transmembrane region [100]. Once modified, CAR T cells are expanded and infused back to lymphodepleted cancer patients where they can eradicate the cancer [89]. CAR-expressing T (CAR-T) cells have shown remarkable efficacy targeting CD19 on B-cell malignancies [102]. The most investigated CAR target is CD19 expressing on normal B cells and the majority of B cell leukemia's and lymphomas [103]. In refractory or relapsed ALL, patients can get $90 \%$ complete remission after reinfused with anti-CD19 CAR T cells. Promising results have also been observed in some refractory diffuse large B cell lymphoma (DLBCL) and chronic lymphocytic leukemia (CLL) [12]. However, this therapy's widespread to solid tumors is one of the major future goals of ACT because of the difficulties to find suitable target antigens and also for the tumor immunosuppression and complex tumor microenvironment [90, 104]. In addition, ACT needs to be optimized to reduce toxicity and to enhance anti-tumor efficacy $[105,106]$.

\section{Immune checkpoint blockade therapy}

Immune checkpoint inhibitors are a class of drugs aimed to increase immune response against cancer cells [107-109]. The immune system consists of various checkpoint pathways focusing on T-cell activation that play an important role in modulating anti-tumor immunity [110]. Molecules that play a crucial role in checkpoint regulation include the T-cell surface molecules CTLA-4, PD-1, T-cell immunoglobulin and mucin domain containing protein 3 (Tim-3), and lymphocyte activation gene-3
(LAG-3) [88]. Tumor expressions of these markers will results in hyporesponsiveness or even exhaustion of the immune system [111]. As a result, these molecules are highly attractive as targets for removing the inhibition and enable cytotoxic T cells to attack cancer cell for destruction [34, 57]. In 2011, FDA approved anti-CTLA-4 antibodies ipilimumab for the treatment of metastatic melanoma, which marked the beginning of a new era for cancer immunotherapy [89, 111]. Subsequently, antibodies against PD-1 pembrolizumab and nivolumab have been approved in 2014, also for the metastatic melanoma [112]. Nivolumab has also been approved in 2015 for previously treated advanced or metastatic squamous lung cancer, an approval later expanded also to small cell lung cancer [113]. In 2016, anti-PD-L1 atezolizumab was approved for bladder cancer [114] and nivolumab was approved for Hodgkin lymphoma [115]. At present, more than 100 clinical trials are ongoing to test the efficacy and safety of immune checkpoint blockers in several cancer types (Table 2) [90, 110, 116-118]. Checkpoint inhibition is also associated with a unique spectrum of side effects including gastrointestinal, dermatologic, endocrine, hepatic, and other less common inflammatory events $[119,120]$. Treatment of moderate or severe side effects requires interruption of the checkpoint inhibitor and the use of corticosteroid $[119,120]$.

\section{Monitoring the response of immunotherapy}

To monitor the immune response, abundant of assays have been tried. Since the immune system is a very complex network, it is crucial to monitor the cell milieu, phenotype of cell subsets, cell surface molecules responsible for cell-cell interactions and intracellular signaling events of the immune system

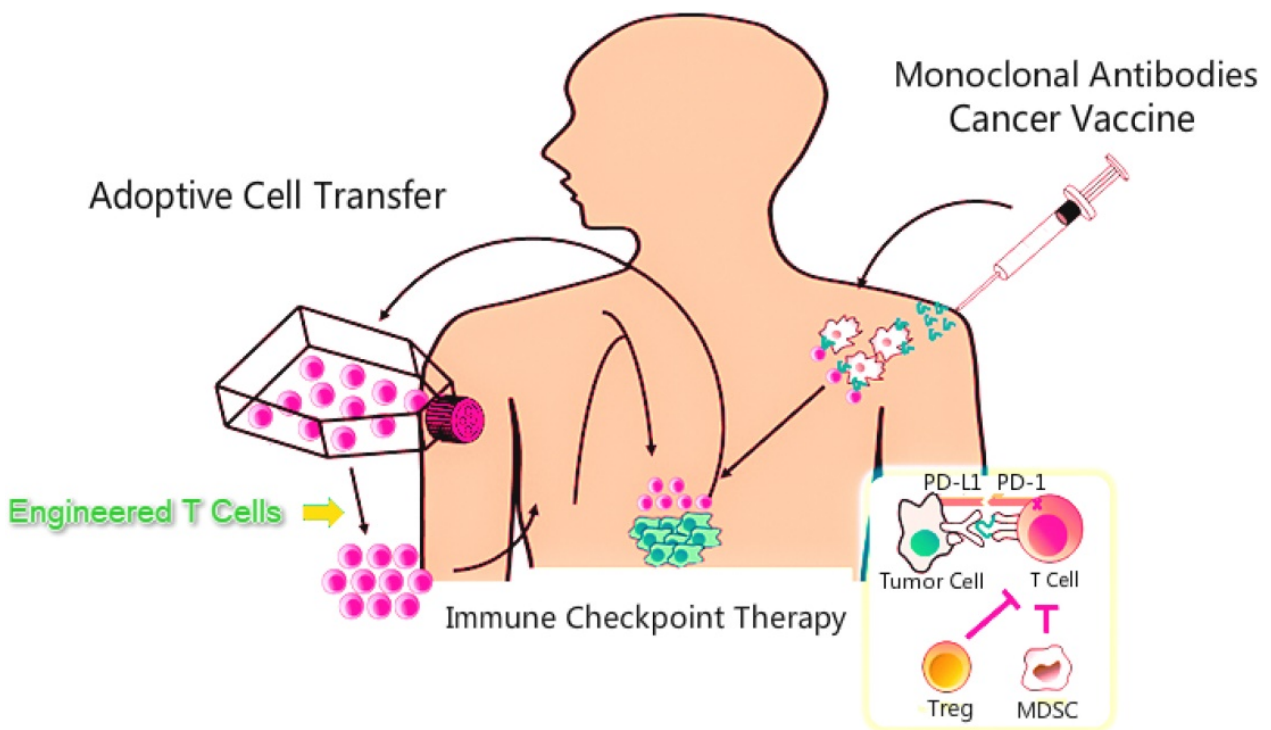

Figure 3. Methods of immunotherapy. MDSC, myeloid-derived suppressor cells; PD-1, programmed death-1; PD-L1, programmed death-ligand 1 
[121-123]. Several methods such as mass cytometry, direct labeling, imaging techniques can be used [122, 124, 125]. Though there are criteria of clinical response of in cancer treatment, there are no specific criteria of monitoring the immunotherapy up to date [7]. Genetic markers, tumor size changes, new tumor lesions, adverse effect, patients' survival are important indications in the clinical trials by immunotherapy [126, 127].

Table 2. Checkpoint Blockade Targets in Clinical Development

\begin{tabular}{llll}
\hline Target & Drug name & Cancer types & Current Status \\
\hline CTLA-4 & Ipilimumab & Melanoma & FDA approved \\
& & Multiple cancers & Phase I-III \\
& Tremelimumab & Multiple cancers & Phase I-III \\
PD-1 & Nivolumab & Melanoma, lung & FDA approved \\
& & Multiple cancers & Phase I-III \\
& Pembrolizumab & Melanoma & FDA approved \\
& & Multiple cancers & Phase I-III \\
& MED10680 & Multiple cancers & Phase I \\
& AMP-224 & Multiple cancers & Phase I \\
PD-L1 & Pidilizumab & Multiple cancers & Phase I-II \\
& MED14736 & Multiple cancers & Phase I-III \\
& Avelumab & Multiple cancers & Phase III \\
& BMS-936559 & Multiple cancers & Phase I-III \\
LAG-3 & IMP321 & Multiple cancers & Phase I \\
& BMS-986016 & Multiple cancers & Phase I \\
B7-H3 & Enoblituzumab & Melanoma, prostate & Phase I \\
\hline
\end{tabular}

CTLA-4, cytotoxic T-lymphocyte antigen 4; LAG-3, lymphocyte activation gene-3; PD-1, programmed death-1; PD-L1, programmed death-ligand 1

\section{Challenges and future directions}

Numbers of challenges of cancer immunotherapy still exist for translating these promising approaches to clinically feasible therapies that treat a larger range of cancer types though recent years' success.

\section{Implementation of next-generation sequencing technologies}

Caner is genomically unstable [128]. Altered ploidy, heterogeneity and normal contamination are the features characterizing the cancer sequencing data that prompt the need for new bioinformatics approaches [128]. Next-generation sequencing (NGS) can provide novel and insights into the molecular machinery inside the cancer cells [129]. Besides expression profiling of transcripts and genes as well as detecting alternative splicing, it has enabled the discovery of single nucleotide variants (SNV), insertions, deletions, amplifications and interchromosomal rearrangements in the whole genome and transcriptome [130]. The advent of NGS and improvements in bioinformatic algorithms that predict immunogenicity of the mutated genes wound certainly lead to the development of more safe, efficient and effective personalized cancer therapy $[3$, 90, 131].

\section{Biomarker-driven clinical trials}

In the process of cancer progression, tumors will acquire somatic mutations, and those cells that acquire certain mutations have survival advantages and will dominate localized tumor areas by displacing those lacking these genomic alterations [132, 133]. Driver mutations dominate in all metastatic sites of cancer and the heterogeneity will certainly affects subclonal mutations [134]. Tumor heterogeneity (both inter- and intra-tumor heterogeneity), together with the clonal mutations are the main challenges of personalized cancer treatment [135]. Therefore, repeated biopsies at progression and biomarkerdriven personalized therapies are needed to determine resistant mechanisms and their potential targeted inhibition [136]. Next-generation clinical trials taking into account the premise of tumor heterogeneity using genomic analysis of circulating cancer cells and circulating-free DNA are being developed [132, 137].

\section{Combinational immunotherapy}

The combination of different immune checkpoint inhibitors such as anti-CTLA-4 and anti-PD-1 have demonstrated enhanced efficacy; however, how to treat with the most suitable dosing and how to identify the most efficacious combinations are the main challenges. In addition, combining immunotherapy with other types of treatment such as chemotherapy, radiation therapy and targeted therapies can also be explored [138-140]. Preliminary evidences indicated that there will be promising synergistic effects when combining other types of therapies with immunotherapy [138, 141].

\section{Conclusions}

In summary, with the advent of cancer immunotherapy and recent advances of it, curing cancer seems to be a real possibility for cancer patients. The development of cancer vaccines, CAR-T cell and checkpoint inhibitors has revolutionized the cancer treatment. Combination therapy might be a promising therapeutic strategy to treat cancer in the future. Recognition and management of toxicities of cancer immunotherapy will also be a key factor for treatment success. Personalized combination therapies that specifically drive each patient' cancer biology via new techniques will be the most promising strategies for cancer treatment.

\section{Competing Interests}

The authors have declared that no competing interest exists. 


\section{References}

1. Rius M, Lyko F. Epigenetic cancer therapy: rationales, targets and drugs. Oncogene. 2012; 31: 4257-65.

2. Sharma P, Hu-Lieskovan S, Wargo JA, Ribas A. Primary, Adaptive, and Acquired Resistance to Cancer Immunotherapy. Cell. 2017; 168: 707-23.

3. Borghaei H, Smith MR, Campbell KS. Immunotherapy of cancer. European journal of pharmacology. 2009; 625: 41-54.

4. Barton MK. Daily aspirin may reduce mortality from prostate cancer with risk of high recurrence. CA: a cancer journal for clinicians. 2015; 65: 83-4.

5. Adusumilli PS, Cha E, Cornfeld M, Davis T, Diab A, Dubensky TW, Jr., et al. New Cancer Immunotherapy Agents in Development: a report from an associated program of the 31stAnnual Meeting of the Society for Immunotherapy of Cancer, 2016. Nature nanotechnology. 2017; 5: 50.

6. Subramaniam DS, Liu SV, Giaccone G. Novel approaches in cancer immunotherapy. Discovery medicine. 2016; 21: 267-74.

7. Lesterhuis WJ, Haanen JB, Punt CJ. Cancer immunotherapy--revisited. Nature reviews Drug discovery. 2011; 10: 591-600

8. de Miguel-Luken MJ, Mansinho A, Boni V, Calvo E. Immunotherapy-based combinations: current status and perspectives. Current opinion in oncology. 2017.

9. Halmos B, Perez-Soler R, Zang X, Choi BK, Kim SH, Kim YH, et al. Cancer immunotherapy using tumor antigen-reactive $\mathrm{T}$ cells. Clinical cancer research: an official journal of the American Association for Cancer Research. 2018; 10: 235-45.

10. Mellman I, Coukos G, Dranoff G. Cancer immunotherapy comes of age. Nature. 2011; 480: 480-9.

11. Voena C, Chiarle R. Advances in cancer immunology and cancer immunotherapy. Discovery medicine. 2016; 21: 125-33.

12. Maude SL, Frey N, Shaw PA, Aplenc R, Barrett DM, Bunin NJ, et al. Chimeric antigen receptor $\mathrm{T}$ cells for sustained remissions in leukemia. The New England journal of medicine. 2014; 371: 1507-17.

13. Ribas A. Releasing the Brakes on Cancer Immunotherapy. The New England journal of medicine. 2015; 373: 1490-2.

14. Sznol M, Longo DL. Release the hounds! Activating the T-cell response to cancer. The New England journal of medicine. 2015; 372: 374-5.

15. Dear AE. Epigenetic Modulators and the New Immunotherapies. The New England journal of medicine. 2016; 374: 684-6.

16. Zaretsky JM, Garcia-Diaz A, Shin DS, Escuin-Ordinas H, Hugo W, Hu-Lieskovan S, et al. Mutations Associated with Acquired Resistance to PD-1 Blockade in Melanoma. The New England journal of medicine. 2016; 375: 819-29.

17. Sukari A, Nagasaka M, Al-Hadidi A, Lum LG. Cancer Immunology and Immunotherapy. Anticancer research. 2016; 36: 5593-606.

18. Zugazagoitia J, Guedes C, Ponce S, Ferrer I, Molina-Pinelo S, Paz-Ares L. Current Challenges in Cancer Treatment. Clinical therapeutics. 2016; 38: 1551-66.

19. Sultan M, Coyle KM, Vidovic D, Thomas ML, Gujar S, Marcato P. Hide-and-seek: The interplay between cancer stem cells and the immune system. Carcinogenesis. 2016.

20. Podack ER, Munson GP. Killing of Microbes and Cancer by the Immune System with Three Mammalian Pore-Forming Killer Proteins. Frontiers in immunology. 2016; 7: 464.

21. Dunn-Pirio AM, Vlahovic G. Immunotherapy approaches in the treatment of malignant brain tumors. Cancer. 2016.

22. Kakavand H, Rawson RV, Pupo GM, Yang JYH, Menzies AM, Carlino MS, et al. PD-L1 expression and immune escape in melanoma resistanceto MAPK inhibitors. Clinical cancer research: an official journal of the American Association for Cancer Research. 2017.

23. Bielinska AU, Makidon PE, Janczak KW, Blanco LP, Swanson B, Smith DM, et al. Distinct pathways of humoral and cellular immunity induced with the mucosal administration of a nanoemulsion adjuvant. Journal of immunology (Baltimore, Md: 1950). 2014; 192: 2722-33.

24. Tsiantoulas D, Diehl CJ, Witztum JL, Binder CJ. B cells and humoral immunity in atherosclerosis. Circulation research. 2014; 114: 1743-56.

25. Berek C. Eosinophils: important players in humoral immunity. Clinical and experimental immunology. 2016; 183: 57-64.

26. Tan TT, Coussens LM. Humoral immunity, inflammation and cancer. Current opinion in immunology. 2007; 19: 209-16.

27. Ponte JF, Ponath P, Gulati R, Slavonic M, Paglia M, O'Shea A, et al. Enhancement of humoral and cellular immunity with an anti-glucocorticoid-induced tumour necrosis factor receptor monoclonal antibody. Immunology. 2010; 130: 231-42.

28. Knutson KL, Disis ML. Augmenting T helper cell immunity in cancer. Current drug targets Immune, endocrine and metabolic disorders. 2005; 5: 365-71.

29. Dranoff G. Cytokines in cancer pathogenesis and cancer therapy. Nature reviews Cancer. 2004; 4: 11-22.

30. Lakshmi Narendra B, Eshvendar Reddy K, Shantikumar S, Ramakrishna S. Immune system: a double-edged sword in cancer. Inflammation research: official journal of the European Histamine Research Society [et al]. 2013; 62: 823-34.

31. Woo SR, Corrales L, Gajewski TF. Innate immune recognition of cancer. Annual review of immunology. 2015; 33: 445-74.
32. Binder RJ. Functions of heat shock proteins in pathways of the innate and adaptive immune system. Journal of immunology (Baltimore, Md: 1950). 2014; 193: $5765-71$.

33. Liu Y, Zeng G. Cancer and innate immune system interactions: translational potentials for cancer immunotherapy. Journal of immunotherapy (Hagerstown, Md: 1997). 2012; 35: 299-308.

34. Kakimi K, Karasaki T, Matsushita H, Sugie T. Advances in personalized cancer immunotherapy. Breast cancer (Tokyo, Japan). 2016.

35. Aldarouish $\mathrm{M}$, Wang $\mathrm{C}$. Trends and advances in tumor immunology and lung cancer immunotherapy. Journal of experimental \& clinical cancer research: CR. 2016; 35: 157.

36. Salimu J, Spary LK, Al-Taei S, Clayton A, Mason MD, Staffurth J, et al. Cross-Presentation of the Oncofetal Tumor Antigen 5T4 from Irradiated Prostate Cancer Cells--A Key Role for Heat-Shock Protein 70 and Receptor CD91. Cancer immunology research. 2015; 3: 678-88.

37. Guillerme JB, Boisgerault N, Roulois D, Menager J, Combredet C, Tangy F, et al. Measles virus vaccine-infected tumor cells induce tumor antigen cross-presentation by human plasmacytoid dendritic cells. Clinical cancer research: an official journal of the American Association for Cancer Research. 2013; 19: 1147-58.

38. Hanlon DJ, Aldo PB, Devine L, Alvero AB, Engberg AK, Edelson R, et al. Enhanced stimulation of anti-ovarian cancer CD8(+) T cells by dendritic cells loaded with nanoparticle encapsulated tumor antigen. American journal of reproductive immunology (New York, NY: 1989). 2011; 65: 597-609.

39. Accolla RS, Tosi G. Optimal MHC-II-restricted tumor antigen presentation to CD4+ T helper cells: the key issue for development of anti-tumor vaccines. Journal of translational medicine. 2012; 10: 154

40. Zhu Z, Cuss SM, Singh V, Gurusamy D, Shoe JL, Leighty R, et al. CD4+ T Cell Help Selectively Enhances High-Avidity Tumor Antigen-Specific CD8+ T Cells. Journal of immunology (Baltimore, Md: 1950). 2015; 195: 3482-9.

41. Haabeth OA, Lorvik $\mathrm{KB}$, Yagita $\mathrm{H}$, Bogen $\mathrm{B}$, Corthay A. Interleukin-1 is required for cancer eradication mediated by tumor-specific Th1 cells. Oncoimmunology. 2016; 5: e1039763.

42. Brehm C, Huenecke S, Esser R, Kloess S, Quaiser A, Betz S, et al. Interleukin-2-stimulated natural killer cells are less susceptible to mycophenolate mofetil than non-activated NK cells: possible consequences for immunotherapy. Cancer immunology, immunotherapy: CII. 2014; 63: 821-33.

43. Becker PS, Suck G, Nowakowska P, Ullrich E, Seifried E, Bader P, et al. Selection and expansion of natural killer cells for NK cell-based immunotherapy. Cancer immunology, immunotherapy: CII. 2016; 65: 477-84.

44. Conway EM, Pikor LA, Kung SH, Hamilton MJ, Lam S, Lam WL, et al. Macrophages, Inflammation, and Lung Cancer. American journal of respiratory and critical care medicine. 2016; 193: 116-30.

45. Genin M, Clement F, Fattaccioli A, Raes M, Michiels C. M1 and M2 macrophages derived from THP-1 cells differentially modulate the response of cancer cells to etoposide. BMC cancer. 2015; 15: 577.

46. Ning C, Xie B, Zhang L, Li C, Shan W, Yang B, et al. Infiltrating Macrophages Induce ERalpha Expression through an IL17A-mediated Epigenetic Mechanism to Sensitize Endometrial Cancer Cells to Estrogen. Cancer research. 2016; 76: 1354-66.

47. Twardowski P, Kanaya N, Frankel P, Synold T, Ruel C, Pal SK, et al. A phase I trial of mushroom powder in patients with biochemically recurrent prostate cancer: Roles of cytokines and myeloid-derived suppressor cells for Agaricus bisporus-induced prostate-specific antigen responses. Cancer. 2015; 121: 2942-50.

48. Wang J, Su X, Yang L, Qiao F, Fang Y, Yu L, et al. The influence of myeloid-derived suppressor cells on angiogenesis and tumor growth after cancer surgery. International journal of cancer. 2016; 138: 2688-99.

49. Burnet FM, Fenner F. Genetics and immunology. Heredity. 1948; 2: 289-324

50. Burnet $M$. The newer approach to immunity in its bearing on medicine and biology. British medical journal. 1954; 2: 189-93.

51. Burnet M. The mechanism of immunity. Scientific American. 1961; 204: 58-67.

52. Burnet FM. Immunological specificity. Transactions \& studies of the College of Physicians of Philadelphia. 1962; 30: 1-10.

53. Doll R, Kinlen L. Immunosurveillance and cancer: epidemiological evidence. British medical journal. 1970; 4: 420-2.

54. Keast D. Immunosurveillance and cancer. Lancet (London, England). 1970; 2: 710-2.

55. Papatestas AE, Kark AE. Immunosurveillance and cancer. Lancet (London, England). 1970; 2: 1092

56. MacGregor GA. Cancer and immunosurveillance. Lancet (London, England). 1973; 1: 1185.

57. Shore ND. Advances in the understanding of cancer immunotherapy. BJU international. 2015; 116: 321-9.

58. DuPage M, Mazumdar C, Schmidt LM, Cheung AF, Jacks T. Expression of tumour-specific antigens underlies cancer immunoediting. Nature. 2012; 482: 405-9.

59. Teng MW, Galon J, Fridman WH, Smyth MJ. From mice to humans: developments in cancer immunoediting. The Journal of clinical investigation. 2015; 125 : 3338-46.

60. Schvartsman G, Ferrarotto R, Massarelli E. Checkpoint inhibitors in lung cancer: latest developments and clinical potential. Therapeutic advances in medical oncology. 2016; 8: 460-73. 
61. Mittal D, Gubin MM, Schreiber RD, Smyth MJ. New insights into cancer immunoediting and its three component phases--elimination, equilibrium and escape. Current opinion in immunology. 2014; 27: 16-25.

62. Park J, Kwon M, Shin EC. Immune checkpoint inhibitors for cancer treatment. Archives of pharmacal research. 2016.

63. Khalil DN, Smith EL, Brentjens RJ, Wolchok JD. The future of cancer treatment: immunomodulation, CARs and combination immunotherapy. Nature reviews Clinical oncology. 2016; 13: 273-90.

64. von Rundstedt FC, Necchi A. Current markers and their value in the era of immuno-oncology. Translational andrology and urology. 2017; 6: 1111-6.

65. Munhoz RR, Postow MA. Recent advances in understanding antitumor immunity. F1000Research. 2016; 5: 2545.

66. Dustin ML. Cancer immunotherapy: Killers on sterols. Nature. 2016.

67. Henricks LM, Schellens JH, Huitema AD, Beijnen JH. The use of combinations of monoclonal antibodies in clinical oncology. Cancer treatment reviews. 2015; 41: 859-67.

68. Maleki LA, Baradaran B, Majidi J, Mohammadian M, Shahneh FZ. Future prospects of monoclonal antibodies as magic bullets in immunotherapy. Human antibodies. 2013; 22: 9-13.

69. Jeanbart L, Swartz MA. Engineering opportunities in cancer immunotherapy. Proceedings of the National Academy of Sciences of the United States of America. 2015; 112: 14467-72.

70. Gul N, van Egmond M. Antibody-Dependent Phagocytosis of Tumor Cells by Macrophages: A Potent Effector Mechanism of Monoclonal Antibody Therapy of Cancer. Cancer research. 2015; 75: 5008-13.

71. Maeda E, Urakami K, Shimura K, Kinoshita M, Kakehi K. Charge heterogeneity of a therapeutic monoclonal antibody conjugated with a cytotoxic antitumor antibiotic, calicheamicin. Journal of chromatography A. 2010; 1217: 7164-71.

72. Neumann T, Schneidewind L, Thiele T, Schulze M, Klenner AF, Busemann C, et al. Reduced platelet transfusions and earlier platelet engraftment using alemtuzumab-based conditioning regimen in allogeneic stem cell transplantation. Journal of cancer research and clinical oncology. 2016; 142: 1091-7.

73. Fiegl M, Stauder R, Steurer M, Mian M, Hopfinger G, Brychtova Y, et al. Alemtuzumab in chronic lymphocytic leukemia: final results of a large observational multicenter study in mostly pretreated patients. Annals of hematology. 2014; 93: 267-77.

74. Pivot X, Aulagner G, Blay JY, Fumoleau P, Kaliski A, Sarkozy F, et al. Challenges in the implementation of trastuzumab biosimilars: an expert panel's recommendations. Anti-cancer drugs. 2015; 26: 1009-16.

75. Teillaud JL. From whole monoclonal antibodies to single domain antibodies: think small. Methods in molecular biology (Clifton, NJ). 2012; 911: 3-13.

76. Chen R, Chen B. Brentuximab vedotin for relapsed or refractory Hodgkin's lymphoma. Drug design, development and therapy. 2015; 9: 1729-33.

77. Chen R, Wang F, Zhang H, Chen B. Brentuximab vedotin for treatment of relapsed or refractory malignant lymphoma: results of a systematic review and meta-analysis of prospective studies. Drug design, development and therapy. 2015; 9: 2277-83

78. Chen R, Hou J, Newman E, Kim Y, Donohue C, Liu X, et al. CD30 Downregulation, MMAE Resistance, and MDR1 Upregulation Are All Associated with Resistance to Brentuximab Vedotin. Molecular cancer therapeutics. 2015; 14: 1376-84.

79. Barbet J, Bardies M, Bourgeois M, Chatal JF, Cherel M, Davodeau F, et al. Radiolabeled antibodies for cancer imaging and therapy. Methods in molecular biology (Clifton, NJ). 2012; 907: 681-97.

80. Oak E, Bartlett NL. Blinatumomab for the treatment of B-cell lymphoma. Expert opinion on investigational drugs. 2015; 24: 715-24

81. Buie LW, Pecoraro JJ, Horvat TZ, Daley RJ. Blinatumomab: A First-in-Class Bispecific T-Cell Engager for Precursor B-Cell Acute Lymphoblastic Leukemia. The Annals of pharmacotherapy. 2015; 49: 1057-67.

82. Thill M. New frontiers in oncology: biosimilar monoclonal antibodies for the treatment of breast cancer. Expert review of anticancer therapy. 2015; 15: 331-8.

83. Ye Z, Qian $Q$, Jin $H$, Qian Q. Cancer vaccine: learning lessons from immune checkpoint inhibitors. Journal of Cancer. 2018; 9: 263-8.

84. Speiser DE, Flatz L. Cancer immunotherapy drives implementation science in oncology. Human vaccines \& immunotherapeutics. 2014; 10: 3107-10.

85. Hurley LP, Bridges CB, Harpaz R, Allison MA, ST OL, Crane LA, et al. Physician Attitudes Toward Adult Vaccines and Other Preventive Practices, United States, 2012. Public health reports (Washington, DC: 1974). 2016; 131: 320-30.

86. Knutson KL, Mittendorf EA. Cancer vaccines in the new era of cancer immunotherapy. Vaccine. 2015; 33: 7376.

87. Ye Z, Li Z, Jin H, Qian Q. Therapeutic Cancer Vaccines. Advances in experimental medicine and biology. 2016; 909: 139-67.

88. Makkouk A, Weiner GJ. Cancer immunotherapy and breaking immune tolerance: new approaches to an old challenge. Cancer research. 2015; 75: 5-10.

89. Yang Y. Cancer immunotherapy: harnessing the immune system to battle cancer. The Journal of clinical investigation. 2015; 125: 3335-7.

90. Sathyanarayanan V, Neelapu SS. Cancer immunotherapy: Strategies for personalization and combinatorial approaches. Molecular oncology. 2015; 9: 2043-53.

91. Wong KK, Li WA, Mooney DJ, Dranoff G. Advances in Therapeutic Cancer Vaccines. Advances in immunology. 2016; 130: 191-249.
92. Restifo NP, Dudley ME, Rosenberg SA. Adoptive immunotherapy for cancer: harnessing the T cell response. Nature reviews Immunology. 2012; 12: 269-81.

93. Schmitt TM, Stromnes IM, Chapuis AG, Greenberg PD. New Strategies in Engineering T-cell Receptor Gene-Modified T cells to More Effectively Target Malignancies. Clinical cancer research: an official journal of the American Association for Cancer Research. 2015; 21: 5191-7.

94. Hawkins RE, Gilham DE, Debets R, Eshhar Z, Taylor N, Abken $\mathrm{H}$, et al. Development of adoptive cell therapy for cancer: a clinical perspective. Human gene therapy. 2010; 21: 665-72.

95. Stone JD, Chervin AS, Aggen DH, Kranz DM. T cell receptor engineering. Methods in enzymology. 2012; 503: 189-222.

96. Liu L, Sommermeyer D, Cabanov A, Kosasih P, Hill T, Riddell SR. Inclusion of Strep-tag II in design of antigen receptors for T-cell immunotherapy. Nature biotechnology. 2016; 34: 430-4.

97. Gill S, Kalos M. T cell-based gene therapy of cancer. Translational research: the journal of laboratory and clinical medicine. 2013; 161: 365-79.

98. Park TS, Rosenberg SA, Morgan RA. Treating cancer with genetically engineered T cells. Trends in biotechnology. 2011; 29: 550-7.

99. Chouaib S, Noman MZ, Kosmatopoulos K, Curran MA. Hypoxic stress: obstacles and opportunities for innovative immunotherapy of cancer. Oncogene. 2016.

100. Jackson HJ, Brentjens RJ. Overcoming Antigen Escape with CAR T-cell Therapy. Cancer discovery. 2015; 5: 1238-40.

101. Chen R, Song XT, Chen B. CD19 chimeric antigen receptor T cell therapy for the treatment of $\mathrm{B}$ cell lineage acute lymphoblastic leukemia. Discovery medicine. 2015; 20: 185-90.

102. Kusabuka H, Fujiwara K, Tokunaga Y, Hirobe S, Nakagawa S, Okada N. Highly efficient gene transfer using a retroviral vector into murine $\mathrm{T}$ cells for preclinical chimeric antigen receptor-expressing $\mathrm{T}$ cell therapy. Biochemical and biophysical research communications. 2016; 473: 73-9.

103. Turtle CJ. Chimeric antigen receptor modified T cell therapy for B cell malignancies. International journal of hematology. 2014; 99: 132-40.

104. Klebanoff CA, Rosenberg SA, Restifo NP. Prospects for gene-engineered T cell immunotherapy for solid cancers. Nature medicine. 2016; 22: 26-36.

105. Rosenberg SA, Restifo NP. Adoptive cell transfer as personalized immunotherapy for human cancer. Science (New York, NY). 2015; 348: 62-8.

106. Liu E, Tong Y, Dotti G, Shaim H, Savoldo B, Mukherjee M, et al. Cord blood NK cells engineered to express IL-15 and a CD19-targeted CAR show long-term persistence and potent anti-tumor activity. Leukemia. 2017.

107. Aspeslagh S, Marabelle A, Soria JC, Armand JP. Upcoming innovations in lung cancer immunotherapy: focus on immune checkpoint inhibitors. Chinese clinical oncology. 2015; 4: 48.

108. Jung CY, Antonia SJ. Tumor Immunology and Immune Checkpoint Inhibitors in Non-Small Cell Lung Cancer. Tuberculosis and respiratory diseases. 2018; 81: 29-41.

109. Sasidharan Nair V, Elkord E. Immune checkpoint inhibitors in cancer therapy: a focus on T-regulatory cells. Immunology and cell biology. 2018; 96: 21-33.

110. Checkpoint Inhibitors Boost Power of Antibody-Drug Conjugate. Cancer discovery. 2016; 6:3

111. Barbee MS, Ogunniyi A, Horvat TZ, Dang TO. Current status and future directions of the immune checkpoint inhibitors ipilimumab, pembrolizumab, and nivolumab in oncology. The Annals of pharmacotherapy. 2015; 49: 907-37.

112. Swart M, Verbrugge I, Beltman JB. Combination Approaches with Immune-Checkpoint Blockade in Cancer Therapy. Frontiers in oncology. 2016; 6. 233 .

113. Marrone KA, Brahmer JR. Using Immune Checkpoint Inhibitors in Lung Cancer. Oncology (Williston Park, NY). 2016; 30

114. Kates M, Sopko NA, Matsui H, Drake CG, Hahn NM, Bivalacqua TJ. Immune checkpoint inhibitors: a new frontier in bladder cancer. World journal of urology. 2016; 34: 49-55.

115. Hatae R, Chamoto K. Immune checkpoint inhibitors targeting programmed cell death-1 (PD-1) in cancer therapy. [Rinsho ketsueki] The Japanese journal of clinical hematology. 2016; 57:2224-31.

116. Joshi M, Pal SK, Drabick JJ. Novel approaches in cancer immunotherapy -- a light at the end of the tunnel. Discovery medicine. 2016; 21: 479-87.

117. Lam SS, Zhou F, Hode T, Nordquist RE, Alleruzzo L, Raker J, et al. Advances in strategies and methodologies in cancer immunotherapy. Discovery medicine. 2015; 19: 293-301.

118. Benzon B, Zhao SG, Haffner MC, Takhar M, Erho N, Yousefi $K$, et al. Correlation of B7-H3 with androgen receptor, immune pathways and poor outcome in prostate cancer: an expression-based analysis. Prostate cancer and prostatic diseases. 2016.

119. Abdel-Rahman O, Fouad M. A network meta-analysis of the risk of immune-related renal toxicity in cancer patients treated with immune checkpoint inhibitors. Immunotherapy. 2016; 8: 665-74.

120. Ciccarese C, Alfieri S, Santoni M, Santini D, Brunelli M, Bergamini C, et al. New toxicity profile for novel immunotherapy agents: focus on immune-checkpoint inhibitors. Expert opinion on drug metabolism \& toxicology. 2016; 12: 57-75.

121. Tavare R, Sagoo P, Varama G, Tanriver Y, Warely A, Diebold SS, et al. Monitoring of in vivo function of superparamagnetic iron oxide labelled murine dendritic cells during anti-tumour vaccination. PloS one. 2011; 6: e19662. 
122. Greenplate AR, Johnson DB, Ferrell PB, Jr., Irish JM. Systems immune monitoring in cancer therapy. European journal of cancer (Oxford, England: 1990). 2016; 61: 77-84

123. Lin JM, Li B, Rimmer E, VanRoey M, Jooss K. Enhancement of the anti-tumor efficacy of a GM-CSF-secreting tumor cell immunotherapy in preclinical models by cytosine arabinoside. Experimental hematology. 2008; 36: 319-28.

124. Lucignani G, Ottobrini L, Martelli C, Rescigno M, Clerici M. Molecular imaging of cell-mediated cancer immunotherapy. Trends in biotechnology. 2006; $24: 410-8$.

125. Aarntzen EH, Srinivas M, Radu CG, Punt CJ, Boerman OC, Figdor CG, et al. In vivo imaging of therapy-induced anti-cancer immune responses in humans. Cellular and molecular life sciences: CMLS. 2013; 70: 2237-57.

126. Kono K, Iinuma H, Akutsu Y, Tanaka H, Hayashi N, Uchikado Y, et al. Multicenter, phase II clinical trial of cancer vaccination for advanced esophageal cancer with three peptides derived from novel cancer-testis antigens. Journal of translational medicine. 2012; 10: 141.

127. Jamieson NB, Maker AV. Gene-expression profiling to predict responsiveness to immunotherapy. Cancer gene therapy. 2016.

128. Gupta SK, Jaitly T, Schmitz U, Schuler G, Wolkenhauer O, Vera J. Personalized cancer immunotherapy using Systems Medicine approaches. Briefings in bioinformatics. 2016; 17: 453-67.

129. Charoentong P, Angelova M, Efremova M, Gallasch R, Hackl H, Galon J, et al. Bioinformatics for cancer immunology and immunotherapy. Cancer immunology, immunotherapy: CII. 2012; 61: 1885-903.

130. Mishra S, Sinha S. Immunoinformatics and modeling perspective of $T$ cell epitope-based cancer immunotherapy: a holistic picture. Journal of biomolecular structure \& dynamics. 2009; 27: 293-306

131. Miao D, Van Allen EM. Genomic determinants of cancer immunotherapy. Current opinion in immunology. 2016; 41: 32-8.

132. Bernicker E. Next-Generation Sequencing and Immunotherapy Biomarkers: A Medical Oncology Perspective. Archives of pathology \& laboratory medicine. 2016; 140: 245-8.

133. Mouw KW, Goldberg MS, Konstantinopoulos PA, D'Andrea AD. DNA Damage and Repair Biomarkers of Immunotherapy Response. Cancer discovery. 2017; 7: 675-93.

134. Olsen LR, Campos B, Barnkob MS, Winther O, Brusic V, Andersen MH. Bioinformatics for cancer immunotherapy target discovery. Cancer immunology, immunotherapy: CII. 2014; 63: 1235-49.

135. Zhou L, Wang K, Li Q, Nice EC, Zhang H, Huang C. Clinical proteomics-driven precision medicine for targeted cancer therapy: current overview and future perspectives. Expert review of proteomics. 2016; 13: 367-81.

136. Sboner A, Elemento O. A primer on precision medicine informatics. Briefings in bioinformatics. 2016; 17: 145-53.

137. Zhu J, Armstrong AJ, Friedlander TW, Kim W, Pal SK, George DJ, et al. Biomarkers of immunotherapy in urothelial and renal cell carcinoma: PD-L1, tumor mutational burden, and beyond. Journal for immunotherapy of cancer. 2018; 6: 4 .

138. Ishihara D, Pop L, Takeshima T, Iyengar P, Hannan R. Rationale and evidence to combine radiation therapy and immunotherapy for cancer treatment. Cancer immunology, immunotherapy: CII. 2016.

139. Cook AM, Lesterhuis WJ, Nowak AK, Lake RA. Chemotherapy and immunotherapy: mapping the road ahead. Current opinion in immunology. 2016; 39: 23-9.

140. Hanoteau A, Moser M. Chemotherapy and immunotherapy: A close interplay to fight cancer? Oncoimmunology. 2016; 5: e1190061.

141. Moy AJ, Tunnell JW. Combinatorial immunotherapy and nanoparticle mediated hyperthermia. Advanced drug delivery reviews. 2017. 